\title{
Effect of a Facing Wall on Façade Flames
}

\author{
AKITO YANAGISAWA ${ }^{1)}$, DAISUKE GOTO ${ }^{1)}$, YOSHIFUMI OHMIYA ${ }^{1)}$, MICHAEL A. \\ DELICHATSIOS ${ }^{2)}$, YEE-PING LEE ${ }^{3)}$ and KAORU WAKATSUKI ${ }^{4)}$ \\ 1) Department of Science and Technology, Tokyo University of Science \\ 2641 Yamazaki, Noda-shi, Chiba 278-8510, Japan \\ 2) FireSERT, The University of Ulster \\ Shore Road, Newtownabbey, Co. Antrim, BT37 0QB, UK \\ 3) Department of Civil and Environment Engineering, Nanya Institute of Technology \\ NO.414,Sec.3, Jhongshan E. Rd., Jhongli City, Taoyuan County 32091, Taiwan \\ 4) National Research Institute of Fire and Disaster \\ 4-35-3 Jindaiji-higashi-machi, Chofu, Tokyo 182-8508, JAPAN
}

\begin{abstract}
If a fire occurs and spreads in a building, fire plumes ejected from the openings may cause fire spread to upper floors and neighboring buildings. In particular, flames ejected from an opening were investigated by many researchers [1-5]. However, most of their works focused on temperature distribution of fire jet plume and heights of the flames issuing from the opening. Although some researchers examined heat transfer from ejected flames to façade wall [6], their studies did not cover situations where there was an opposite wall. In the present study, a series of small-scale experiments having a façade wall and an opposite parallel wall representing an adjacent buildings were carried out in order to investigate flame heights, heat flux to the façade wall and to the facing wall, and temperature distribution of ejected flame from an opening. The following phenomena were examined: 1) the heat release rate at which flames occurred from the opening and 2) the temperature distribution in ejected flames and the heat flux from ejected flames with and without an opposite wall [7].
\end{abstract}

KEYWORDS: ejected flames, compartment fire, heat flux, temperature distribution, facing wall

NOMENCLATURE LISTING

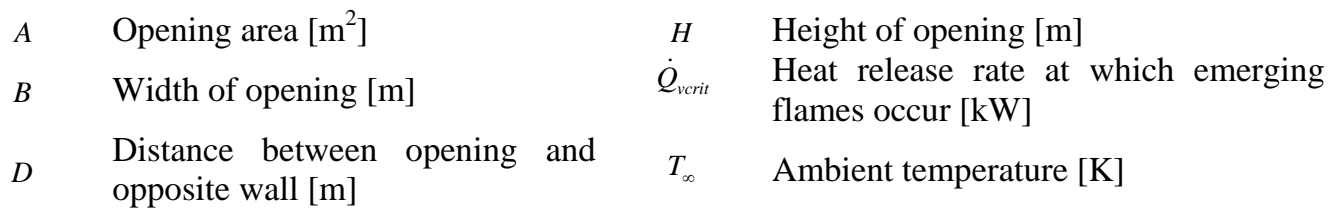

INTRODUCTION

When a fire occurs in a building, the fire damage may extend to adjacent buildings by flames ejected from openings of the building because of the proximity of other buildings. It is necessary to examine the effect on the ejected flames from adjacent building having vertical walls parallel to the façade or normal to it (side wall). And when a comprehensive fire performance design is carried out, it is important to verify prevention of fire spread to upper floors from the floor of fire origin. On the basis of such a background, the influence on the ejected flames owing to a wall facing the opening (facing wall) was investigated in the present study. In particular, the heat fluxes to the façade wall and the opposite wall from flames ejected from an opening, and temperature distribution in ejected flames were investigated by experiments using a small scale model.

\section{DESCRIPTION OF EXPERIMENT}

\section{Experimental apparatus}

Figure 1 shows the experimental setup. Regarding the compartment model, a small-scale $0.5 \mathrm{~m}$ cubic compartment was used with a ceramic board of thickness $0.04 \mathrm{~m}$ shown in Fig. 1 (a). A facing wall in Fig. 1 (b) (0.9 m width $\times 1.8 \mathrm{~m}$ height) which faced the opening of the fire compartment was installed at various distances from the façade wall. Propane gas burner $(0.2 \mathrm{~m}$ width $\mathrm{x} 0.1 \mathrm{~m}$ height $)$ was installed at the center in the fire compartment floor. The gas supply rate was regulated by a gas flow controller. 


\section{Measurements}

\section{a) Temperature distribution of flames ejected from the opening}

A measurement net ( $0.3 \mathrm{~m}$ width $\mathrm{x} 1.8 \mathrm{~m}$ height) centrally located was used to measure the temperature distribution of flames ejected from an opening as shown in Fig. 1 (c). The interval distance between the each thermocouple was every $0.05 \mathrm{~m}$ up to $0.6 \mathrm{~m}$ from the lower edge of opening and every $0.1 \mathrm{~m}$ from 0.6 $\mathrm{m}$ up to $1.8 \mathrm{~m}$ as shown in Fig. 1 (c).

\section{b) Temperature distribution within compartment}

The history of vertical temperature distribution within the fire compartment was measured by two thermocouple trees at two diagonal points $\mathrm{X}$ and $\mathrm{Y}$ as shown in Fig. 1 (c) - (e).

\section{c) Incident heat flux}

Gardon type heat flux gauges (Medtherm LTD.) and steel plate gauges were installed on the façade wall and the facing wall to measure the heat flux at each wall surface. The type of steel plate gauge with thermocouples spot-welded to the back of the steel plate has been employed for heat flux measurement in previous façade tests [7]. The steel plate gauge with dimensions $25 \mathrm{~mm}$ (width) x $25 \mathrm{~mm}$ (Height) x $3 \mathrm{~mm}$ (thickness) was employed in this experiment to measure total heat flux. As shown in Fig. 1 (a) and (b), the steel plate gauges were installed every $0.1 \mathrm{~m}$ above the upper end of the opening in three columns $0.1 \mathrm{~m}$ apart.

\section{d) Heat Release Rate}

The heat release rate supplied was the heat of combustion multiplied by rate of propane gas supplied to the burner. In addition, based on oxygen consumption method, the heat release rate was measured in the duct of the collection hood above the experiment set up. Moreover, the heat release rate when a flame occurred from an opening was recorded from observations on carbon monoxide (CO) measurements.

\section{Experimental procedure}

For first ten minutes, the gas burner was supplied with a steady heat release rate of about 5-10 kW to reduce heat loss at the ceramic walls by preheating them. After ten minutes, the supply rate of the propane gas was gradually raised to a maximum heat release rate of $1800 \mathrm{AH}^{1 / 2} \mathrm{~kW}$ at intervals of two minutes by a step increase of $0.5-2 \mathrm{~kW}$ (see Fig. 2). This maximum heat release rate $\left(1800 \mathrm{AH}^{1 / 2} \mathrm{~kW}\right)$ was coming from multiplication of Kawagoe's stoichiometric burning rate for wood $\left(\approx 0.1 \mathrm{AH}^{1 / 2} \mathrm{~kg} / \mathrm{s}\right)$ within the compartment and heat of combustion of wood $(18,000 \mathrm{~kJ} / \mathrm{kg})$. The heating of compartment lasted till the gas temperature within the fire compartment became almost quasi-steady. In addition, the steel plates heat flux gages had been shielded by a ceramic board until heat flux measurement started [7]. This arrangement allows the determination of heat flux from the rate of change of the heat capacity of the steel plate gauge [7].

\section{Experimental conditions}

The experimental conditions are summarized in Table 1. Three types of openings were installed and the distance $\mathrm{D}$ between the façade wall and the facing wall was changed from $0.1 \mathrm{~m}$ to $0.3 \mathrm{~m}$ (see Fig. 1). The maximum heat release rate was $1800 \mathrm{AH}^{1 / 2} \mathrm{~kW}$ which is expected to be under-ventilated condition. 


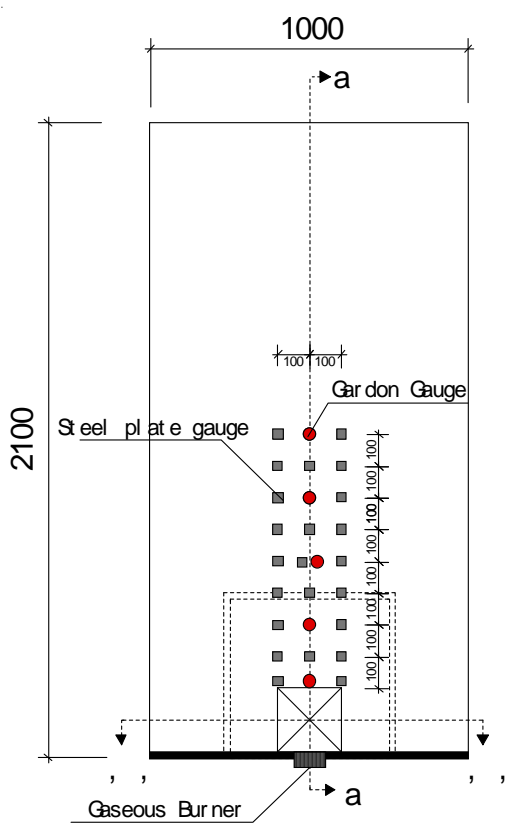

(a-1)Front View(Facade-B0.2m H0.2m)

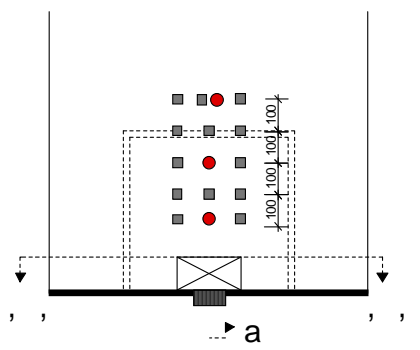

(a-2)Front View(Facade-B0.2m H0.1m)
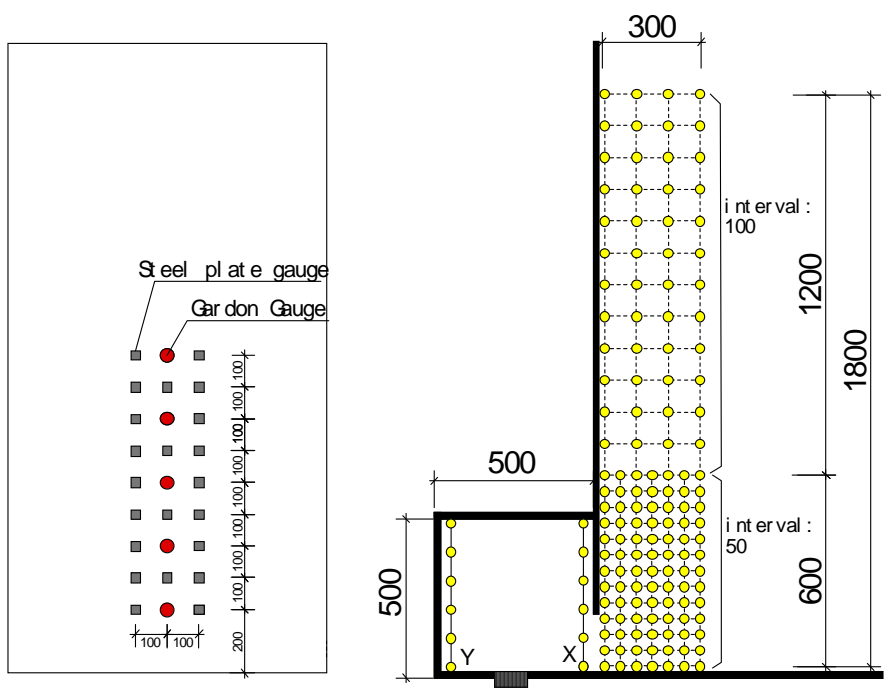

(b)Front View(Facing wall)

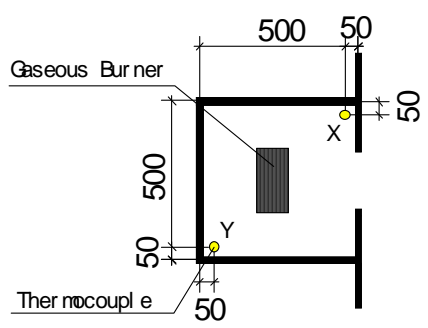

(d)b-b Floor plan(No wall)

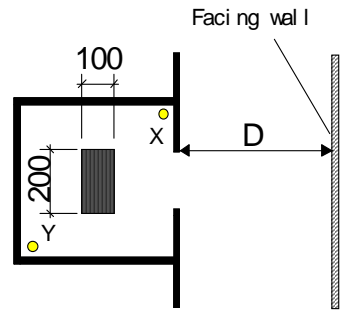

(e)b-b Floor plan(Facing wall)

unit : mm

Fig. 1. Experimental setup

Table 1. Experimental condition

\begin{tabular}{|c|c|c|c|c|c|}
\hline \multirow{2}{*}{$\begin{array}{c}\text { Case } \\
\text { No. }\end{array}$} & \multicolumn{2}{|c|}{ Opening Geometry } & \multirow{2}{*}{$\begin{array}{c}\text { Ventilation Factor } \\
\mathrm{AH}^{1 / 2}\left(\mathrm{~m}^{5 / 2}\right)\end{array}$} & \multirow{2}{*}{$\begin{array}{l}\text { Heat Release Rate } \\
1800 \mathrm{AH}^{1 / 2}(\mathrm{~kW})\end{array}$} & \multirow{2}{*}{$\begin{array}{c}\begin{array}{c}\text { Distance between } \\
\text { two walls }\end{array} \\
\text { D (m) }\end{array}$} \\
\hline & Breath (m) & Height (m) & & & \\
\hline 1 & \multirow{4}{*}{0.2} & \multirow{4}{*}{0.2} & \multirow{4}{*}{$1.8 \times 10^{-2}$} & \multirow{4}{*}{32.2} & - \\
\hline 2 & & & & & 0.3 \\
\hline 3 & & & & & 0.2 \\
\hline 4 & & & & & 0.1 \\
\hline 5 & \multirow{3}{*}{0.2} & \multirow{3}{*}{0.1} & \multirow{3}{*}{$6.3 \times 10^{-3}$} & \multirow{3}{*}{11.4} & - \\
\hline 6 & & & & & 0.3 \\
\hline 7 & & & & & 0.2 \\
\hline
\end{tabular}




\begin{tabular}{|c|c|c|c|c|c|}
\hline 8 & & & & & 0.1 \\
\hline 9 & \multirow{4}{*}{0.1} & \multirow{4}{*}{0.2} & \multirow{4}{*}{$8.9 \times 10^{-3}$} & \multirow{4}{*}{16.1} & - \\
\hline 10 & & & & & 0.3 \\
\hline 11 & & & & & 0.2 \\
\hline 12 & & & & & 0.1 \\
\hline
\end{tabular}

\section{EXPERIMENTAL RESULTS}

\section{Heat release rates}

Figure 2 shows the heat release rates derived from the gas supply rate and from oxygen consumption method without facing wall and opening size B0.2 m x H0.2 m. Tewerson et al. analyzed that yield of carbon monoxide at under-ventilated fire is much higher relative to the one at the well-ventilated fire [8]. And also their results showed $\mathrm{CO}$ and soot yields drastically increased and carbon dioxide $\left(\mathrm{CO}_{2}\right)$ decreased as the equivalence ratio is higher than about 0.6. Therefore, both $\mathrm{CO}$ and $\mathrm{CO}_{2}$ yield measurement and visible observations were utilized to define the transition between ventilated and under-ventilated fire. Figure 3 shows an example of chorological histories CO yield collected in the hood for the same conditions as Fig. 2. The CO yield starts increasing at approximately 20 minutes in Fig. 3, which corresponded the time when flames were visually seen coming out from the opening. Fig. 4 shows the relation between opening factor $\mathrm{AH}^{1 / 2}$ and the heat release rate $\left(\mathrm{Q}_{\text {vcrit }}\right)$ when external flames occurred including the cases with facing wall at distance $\mathrm{D}$. The $\mathrm{Q}_{\mathrm{vcir}}$ is found to be given by;

$\mathrm{Q}_{\mathrm{vcir}}=1500 \mathrm{AH}^{1 / 2}$

This is a new result indicating that the heat release rate at under ventilated conditions is $1500 \mathrm{AH}^{1 / 2}$ as previously reported regardless of the presence of wall [9]. This result is also supported by Fig. 8 as discussed later.

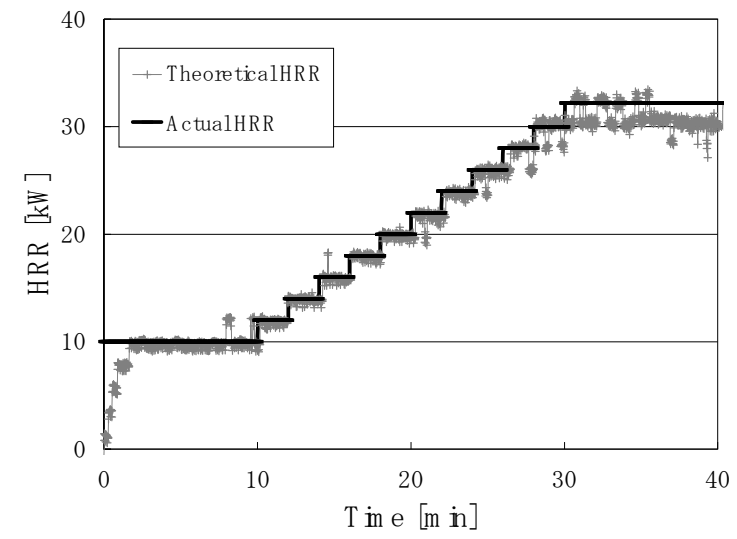

Fig. 2. Heat release rate (Case No.1)

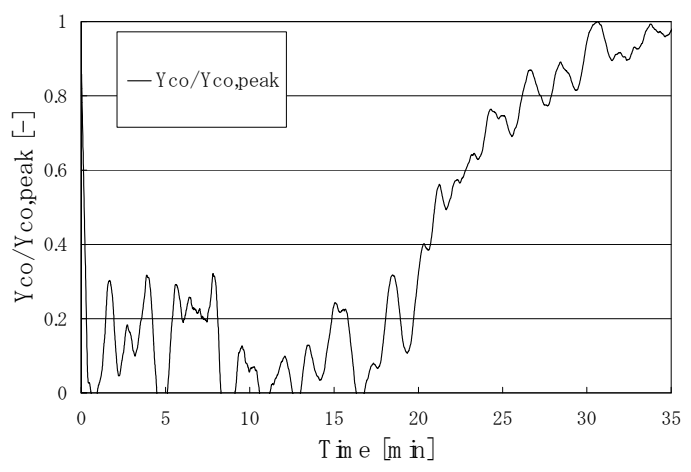

Fig. 3. $\mathrm{Y}_{\mathrm{co}} / \mathrm{Y}_{\mathrm{co} \text {,peak }}($ Case No.1) 


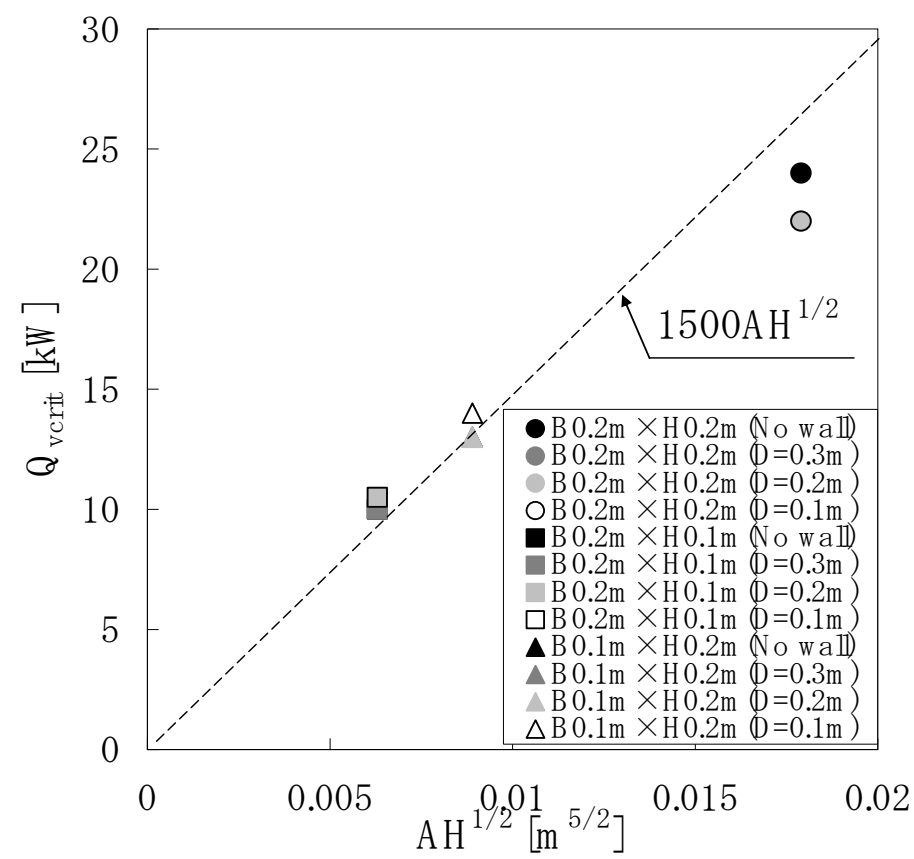

Fig. 4. Heat release rate $\left(\mathrm{Q}_{\mathrm{vcrit}}\right)$ of generation limit of external flame.

\section{Temperature distribution of ejected flame}

With a facing wall at distance D, the temperature distributions of ejected flame are shown in Fig. 5 for each of the three openings and for each separation distance of the façade from the facing wall. Also, the heights of ejected flame between the façade wall and the facing wall are shown in Fig. 6. Flame heights were determined by the location at which the measured gas temperature was $250{ }^{\circ} \mathrm{C}$ and $500{ }^{\circ} \mathrm{C}$ [7]. This criterion for selecting the flame height provided values that correspond to the maximum flame height. As the distance $\mathrm{D}$ between walls is getting shorter, the ejected flames tend to elongate. The reason of this behavior is that air entrainment is restricted as the facing walls come closer. Figure 7 shows the temperature distribution in the compartment as a function of time for different opening conditions. The temperature became almost uniform in the compartment. Finally, Fig. 8 indicates the relation of average maximum temperature in the compartment with and without facing wall. This result shows that the facing wall does not influence the temperature in the compartment, and therefore the inflow of air into fire compartment. This result reinforces the previous observation in Fig. 4 that the facing wall does not change the critical heat release rate at under-ventilated conditions $\left(1500 \mathrm{AH}^{1 / 2}\right)$. 


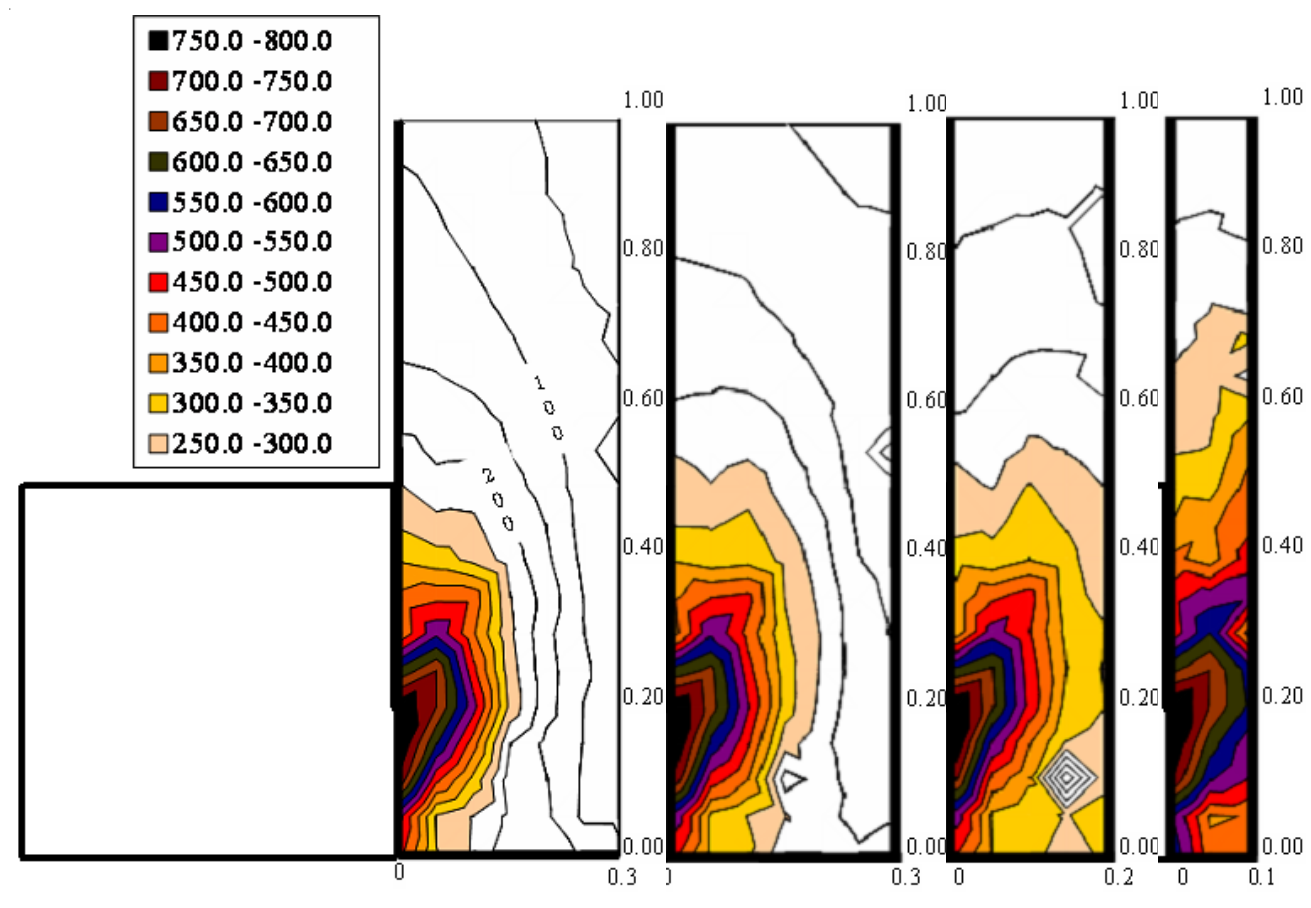

1) Without facing wall 2) $D=0.3 \mathrm{~m}$

3) $D=0.2 \mathrm{~m}$

4) $D=0.1 \mathrm{~m}$

(a) B0.2 $\mathrm{m} \times \mathrm{H} 0.2 \mathrm{~m}$

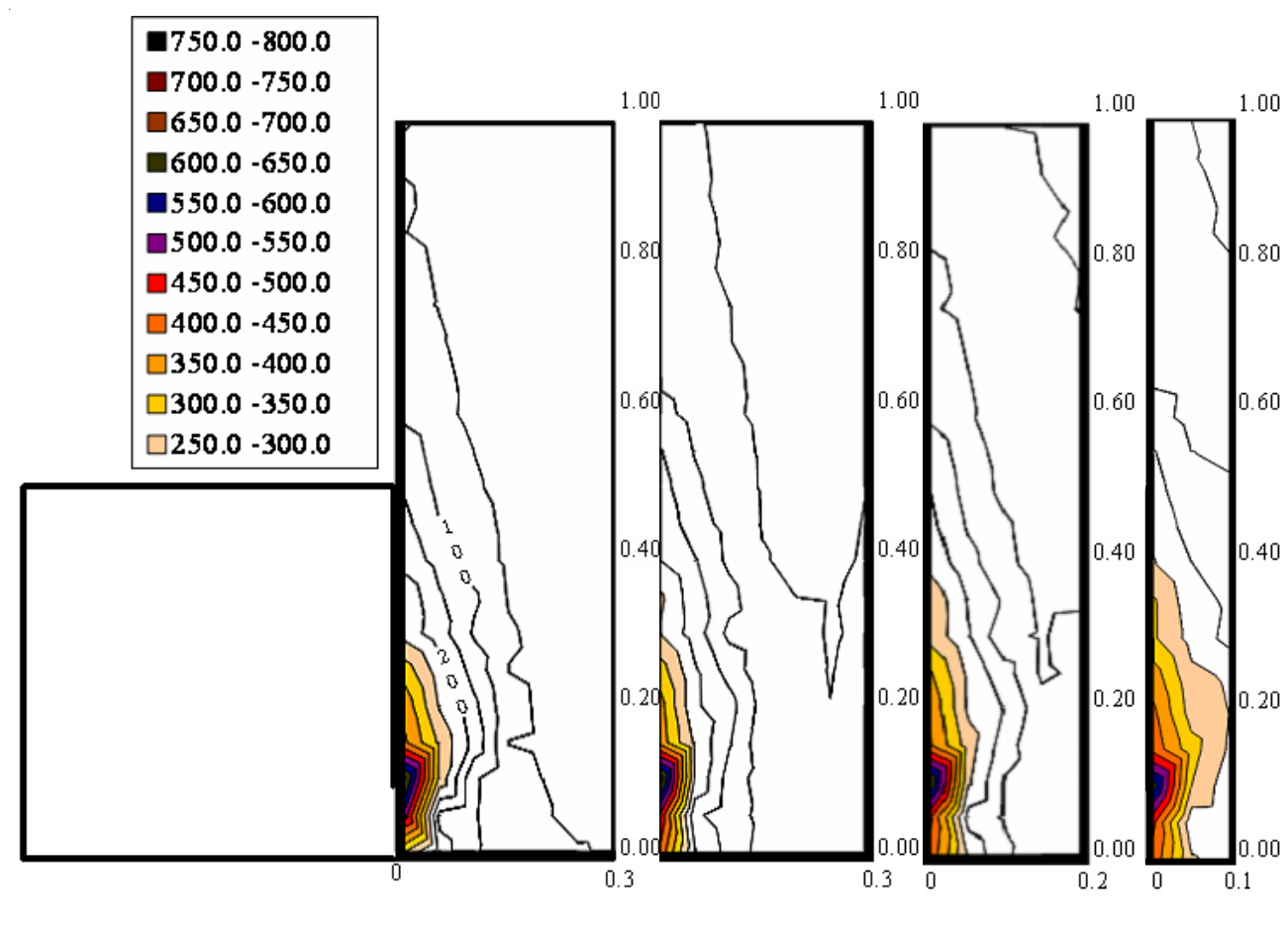

1) Without facing wall 2) $D=0.3 \mathrm{~m}$

3) $D=0.2 \mathrm{~m}$ 4) $\mathrm{D}=0.1 \mathrm{~m}$

(b) B0.2 $\mathrm{m} \times \mathrm{H} 0.1 \mathrm{~m}$ 


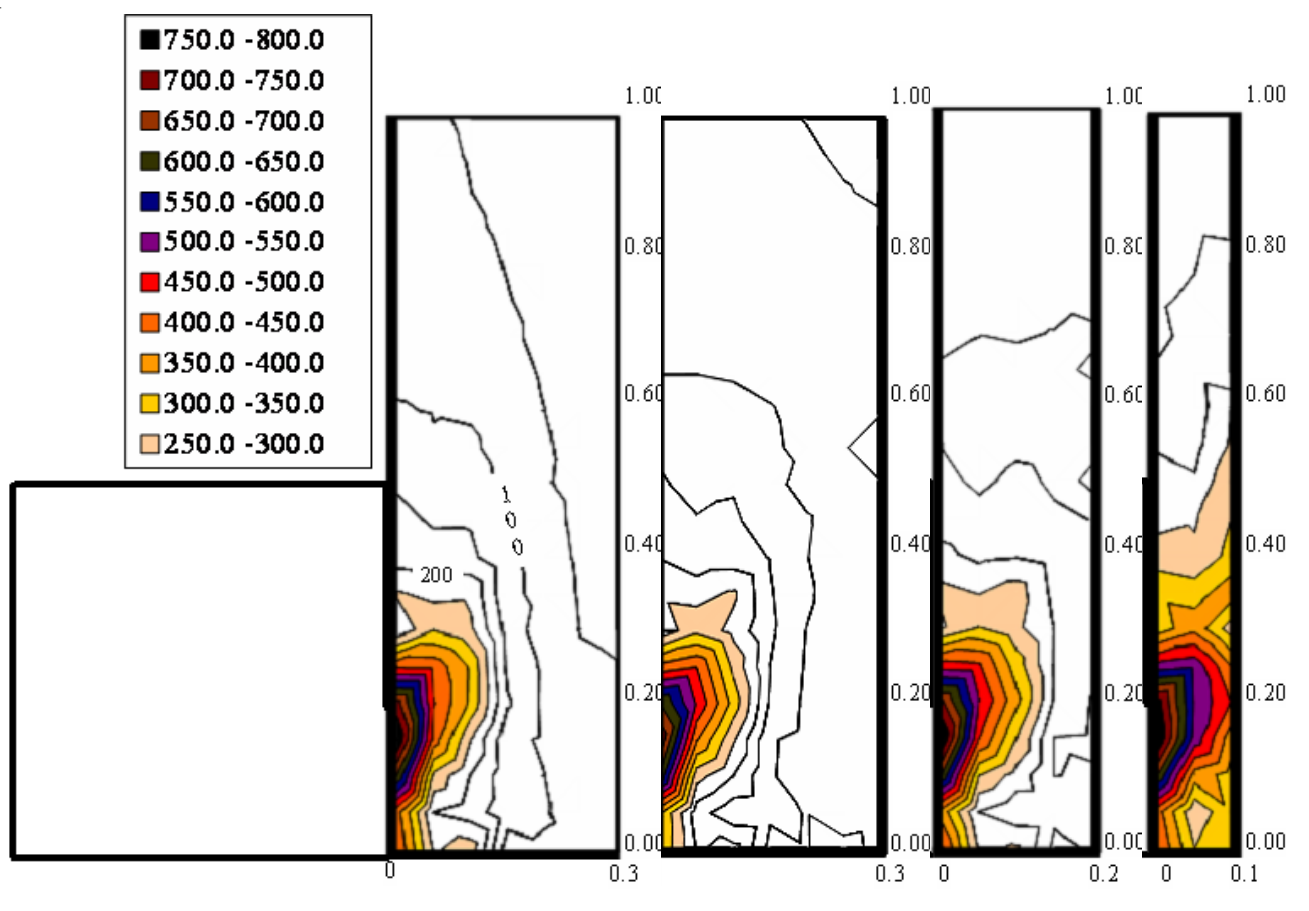

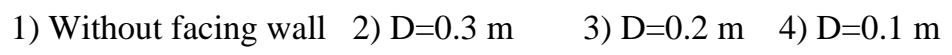
(c) B0.1 m×H0.2 m

Fig. 5. Temperature distribution of ejected flame with opening size

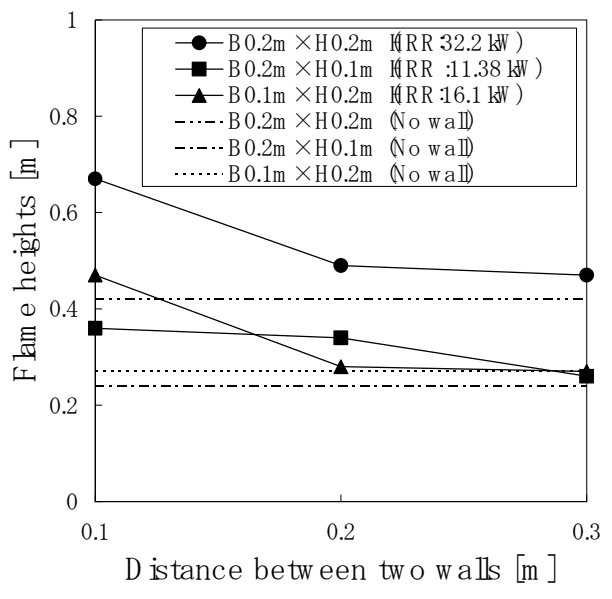

(a) $250{ }^{\circ} \mathrm{C}$

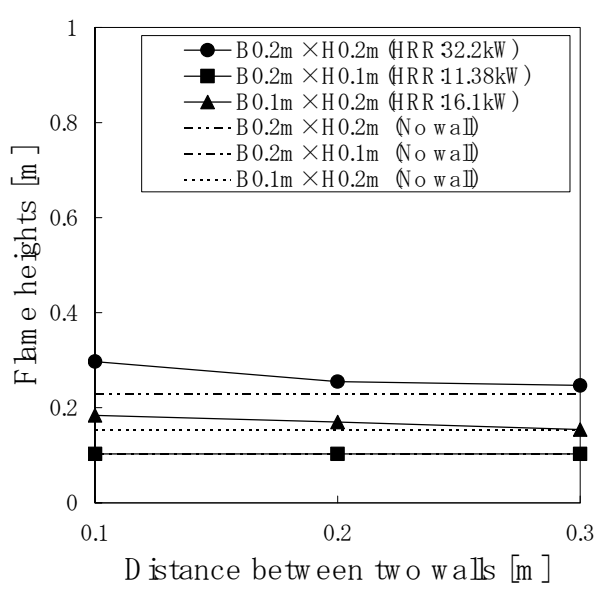

(b) $500{ }^{\circ} \mathrm{C}$

Fig. 6. Flame height measured from neutral plane as a function of distance between compartment and facing walls 


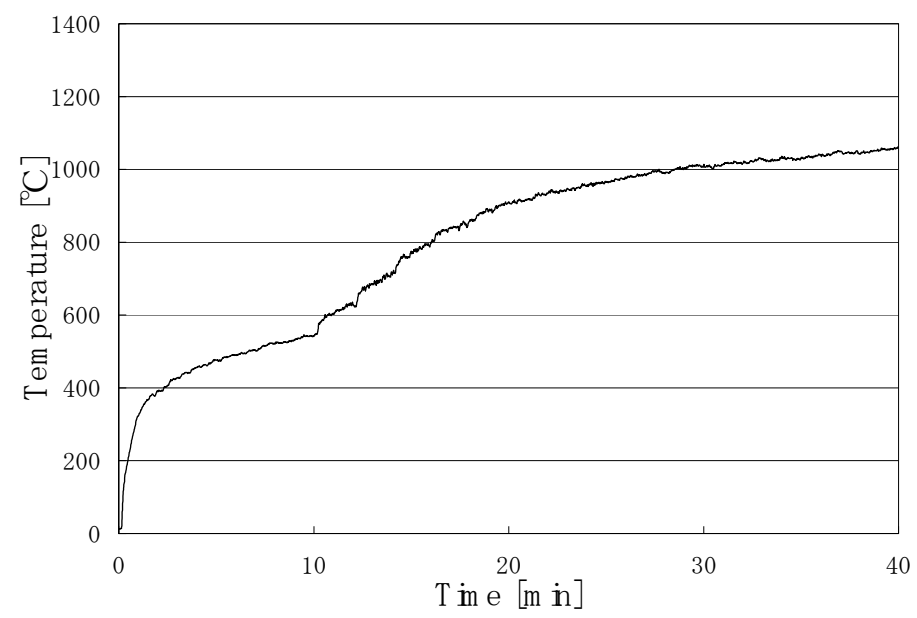

(a) B0.2 m $\times$ H0.2 m

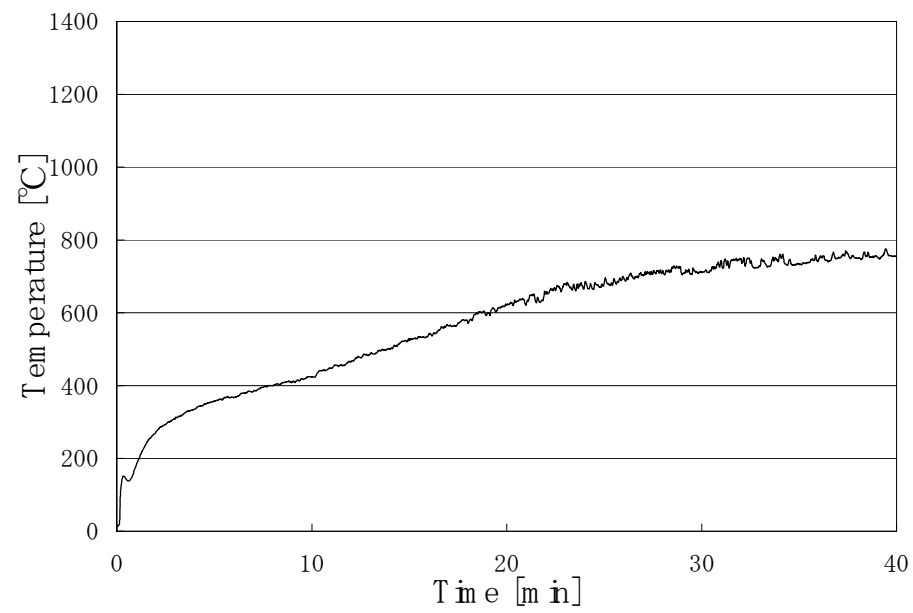

(b) B0.2 m× H0.1 m

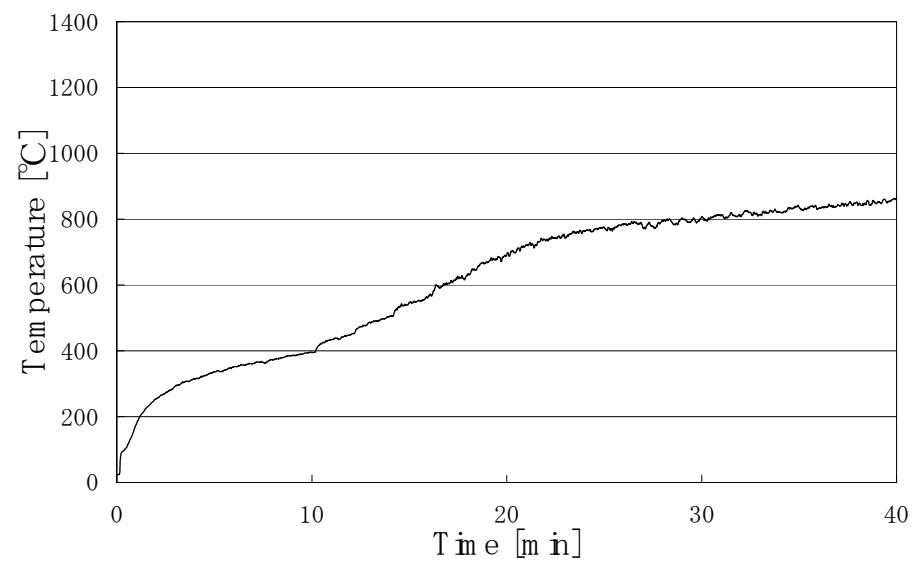

(c) B0.1 m $\times$ H0.2 m

Fig. 7. Mean temperature distributions as function of time inside the compartment with opening size 


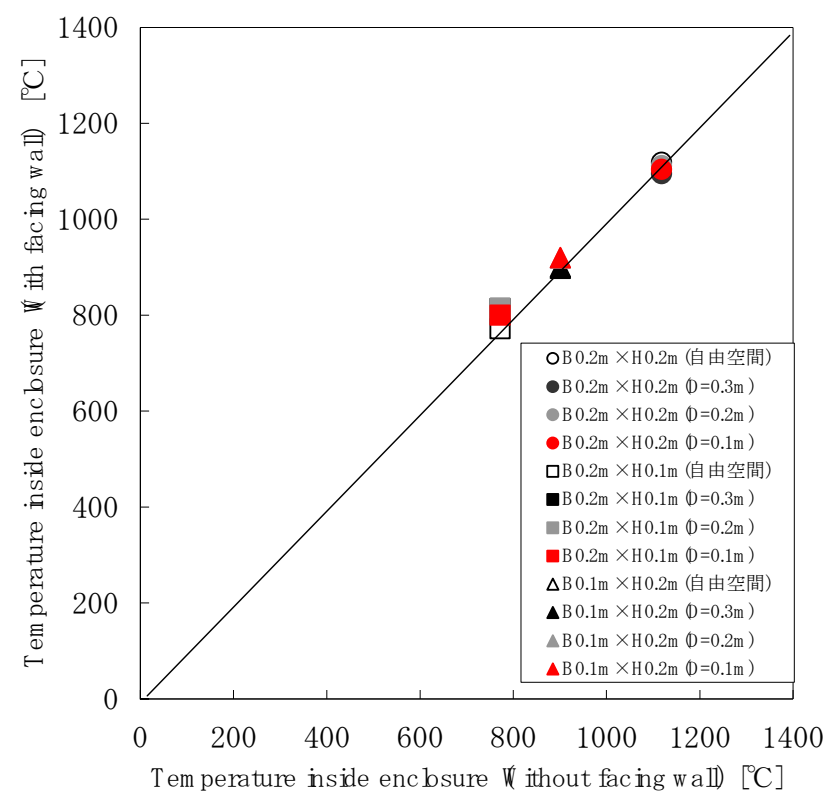

Fig. 8. Relation of average maximum temperature in compartment with and without facing wall

\section{Heat fluxes from the external flames}

The heat fluxes to the façade wall and the facing wall surface are shown in Fig. 9 at different heights only for one opening (B0.2 m x H0.2 m). As the facing wall approaches an opening, the heat flux to each wall increases as shown in Fig. 9. In particular, the increase of the value in the vicinity of the opening is remarkable. Figure 10 shows the heat fluxes plotted against the height normalized by the flame height. The heat fluxes in the flame region $\left(\mathrm{Z} / \mathrm{Z}_{\mathrm{f}} \leqq 1\right)$ shows greater variation from the heat fluxes at $\left(\mathrm{Z} / \mathrm{Z}_{\mathrm{f}}>1\right)$, as the distance between the walls decreases.

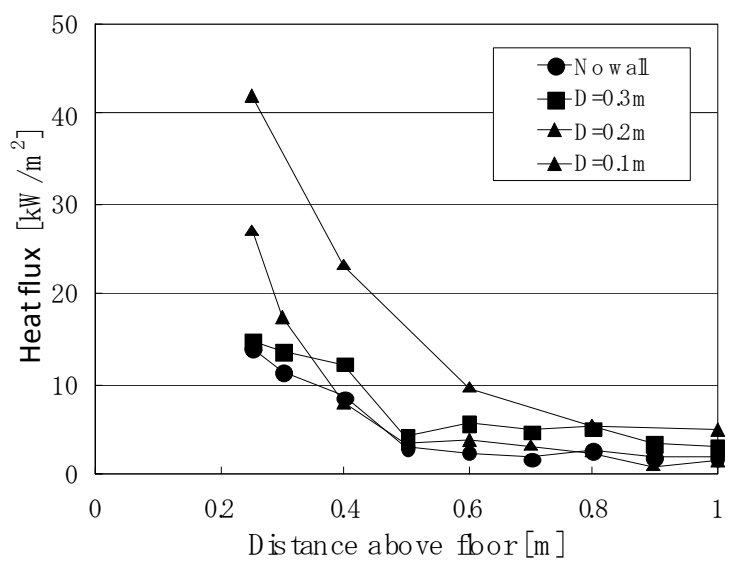

(a) Façade wall

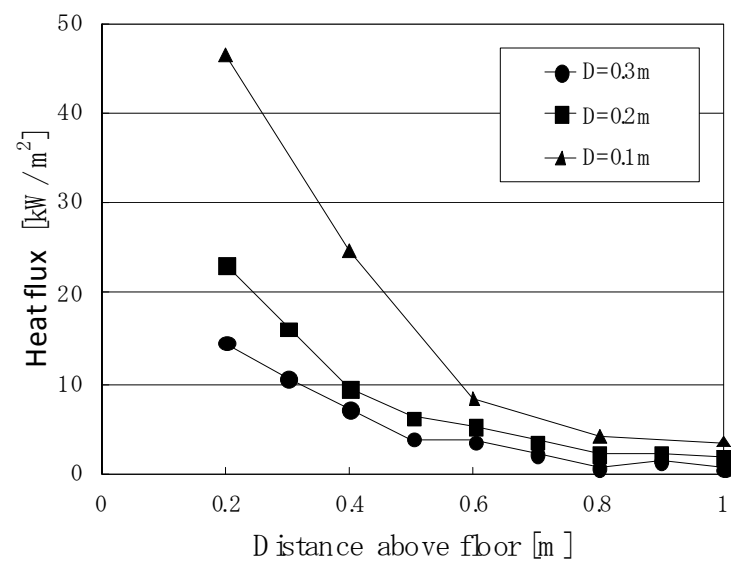

(b) Facing wall

Fig. 9. Heat flux rate to each wall (B0.2 m x H0.2 m) 


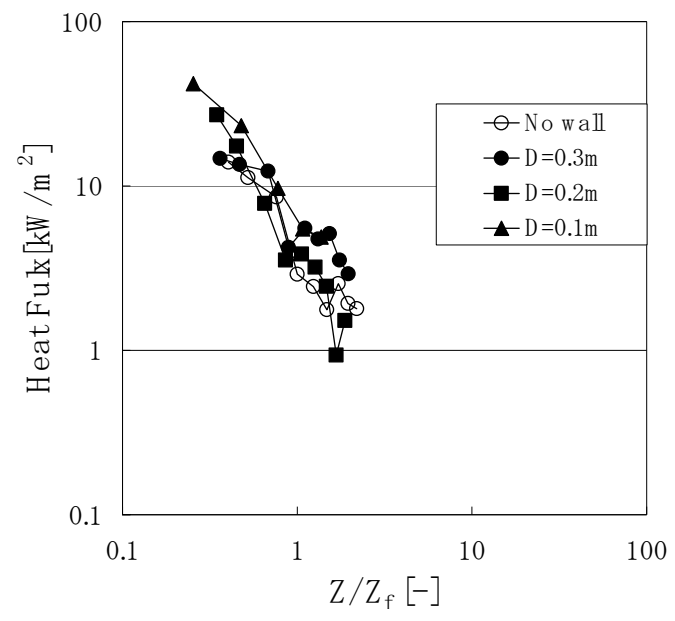

1) $Z_{\mathrm{f}}$ (Flame height at $250^{\circ} \mathrm{C}$ )

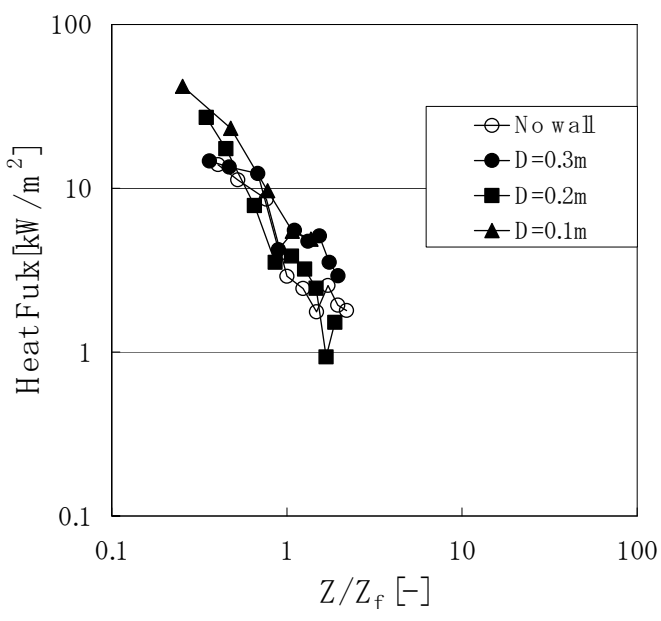

2) $\mathrm{Z}_{\mathrm{f}}$ (Flame height at $500{ }^{\circ} \mathrm{C}$ )

(a) Façade wall

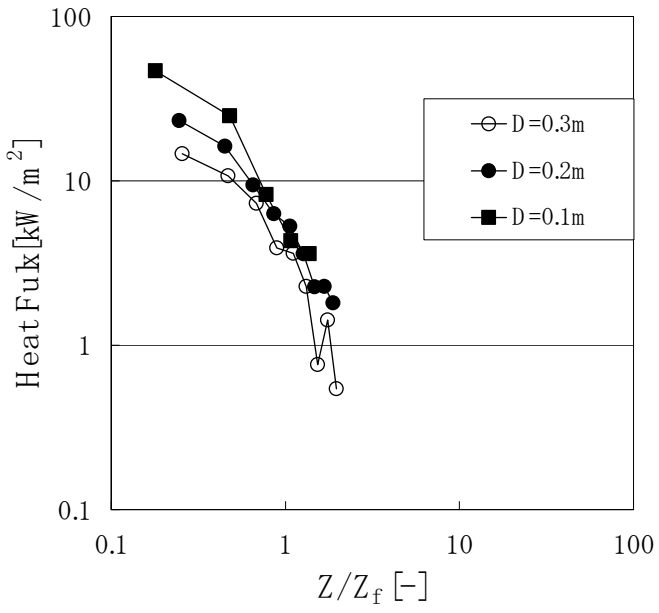

1) $Z_{\mathrm{f}}$ (Flame height at $250^{\circ} \mathrm{C}$ )

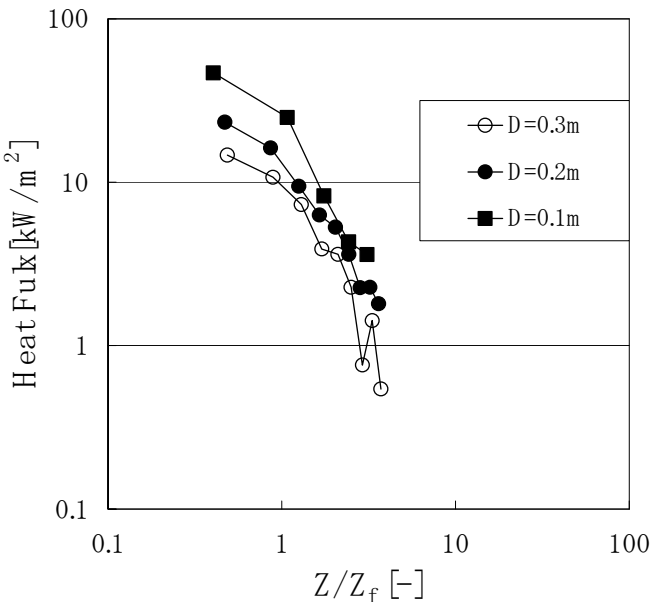

2) $\mathrm{Z}_{\mathrm{f}}$ (Flame height at $500{ }^{\circ} \mathrm{C}$ )

(b) Facing wall

Fig. 10. Non-dimensional height and incident heat flux rate to each wall (B0.2 m x H0.2 m)

\section{CONCLUSIONS}

The effects of a facing wall on flames from enclosure were experimentally investigated.

Flame height, inside and outside temperatures and heat fluxes have been measured. The main conclusion is that the facing wall does not affect the burning inside the enclosure at under-ventilated conditions regardless of its distance from the opening. Specifically, it was found that the critical heat release rate before flames are ejected is $1500 \mathrm{AH}^{1 / 2}$ regardless of the presence of the facing wall. This result is corroborated by the maximum temperature in the compartment with and without facing wall. Correlation of the flame height, temperature, and heat flux data is in progress following the procedure in our previous publications [7,9].

\section{ACKNOWLEDGEMENT}

The authors greatly appreciate financial support to conduct this project from $21^{\text {st }}$ century center of excellence program (COE) of Ministry of Education, Culture, Sports, Science and Technology of Japan. 


\section{REFERENCES}

[1] Shizuo Yokoi: Hot current of air temperature from a window at the time of the fire-resistant Building, Architectural Institute of Japan, No.60, pp.513-516, October, 1958

[2] R.Jansson, B.Onnermark: Flame heights outside openings, FOA Report, C 20445-A3, 1982.5

[3] American Iron and Steel Institute: Flame Safe Structural Steel - A Design Guide, 1979

[4] The Ministry of Construction minister's secretariat technology investigation room supervision ,Japan : Development of the general fire prevention design method of the building, Vol. 2 fire spread prevention design law, 1989

[5] Y. Ohmiya, Y.Hori, K.Sagimori, T.Wakamatsu: Predictive method for properties of flame ejected from an opening incorporating excess fuel, Proceedings of $4^{\text {th }}$ Asia-Oceania Symposium on Fire Science and Technology, pp.375-386, 2000

[6] I.Oleszkiewicz: Heat Transfer from a Window Fire Plume to a Building Facade, HTD - Vol.123, Collected papers in Heat Transfer, Book No.H00526, pp.163-170, 1989

[7] Yee-Ping Lee, M.A.Delichatsios, G.Silcock: Heat Fluxes and Flame Heights in Façade from Fires in Enclosures of Varying Geometry, Proceedings of The Combustion Institute, 31, 2521-2528, 2007.

[8] A. Tewarson, F. H. Jiangb, T. Morikawa: Ventilation-controlled combustion of polymers, Combustion and Flame, 95, 1-2, pp. 151-169, 1993

[9] Yee-Ping Lee, M. A. Delichatsios, Yoshifumi Ohmiya, Kaoru Wakatsuki, Akito Yanagisawa, Daisuke Goto: Flame heights and heat fluxes on building facades and opposing building wall by flames emerging from an opening, Proceedings of the 7th Asia-Oceania Symposium on Fire Science and Technology, Hong Kong, China, Sep. 2007 in press. 
